\title{
Effect of Intra-Muscular Administration of Dexamethasone on the Duration of Induction of Labor in Primigravida Full-Term Pregnancy
}

\author{
Emad Maarouf Abdel Latif, Wael Soliman Taha \& Ahmed Abd Rabou Ali Ahmed* \\ Obstetrics and Gynecology Department, Faculty of Medicine, Al-Azhar University \\ *Corresponding Author: Ahmed Abd Rabou Ali Ahmed, Phone No.: (+2) 01147346106, E-mail: \\ ahmed.elarishy90@gmail.com
}

\begin{abstract}
Background: induction of labor refers to the process of artificially initiating uterine contractions prior to their spontaneous onset to effects progressive effacement and dilatation of the cervix and ultimately, delivery of the baby.

Aim of the Work: to establish whether a single dose of dexamethasone (8mg) intra-muscularly plays a role in shorting the duration interval between initiation of labor induction and beginning of the active phase of labor in primigravida full-term pregnancy.

Patients and Methods: this clinical interventional randomized case-controlled trial was conducted at El Hussien University Hospital during the period from July 2017 to March 2018. One hundred twenty full term \& post-term ( $\geq 40$ weeks) nulliparous women were included in this study and divided into the following: Group I (Dexamethasone group) injected with $2 \mathrm{ml}(8 \mathrm{mg}$ ) of the product (dexamethasone) 6 hours before initiation of labor induction and Group II (Control group) was not receive dexamethasone or any other cervical ripening agent.
\end{abstract}

Results: our results showed that the intramuscular administration of dexamethasone appears to shorten labor duration.

Conclusion: single intra-muscular injection of two $\mathrm{ml}$. (8mg.) of dexamethasone before induction of labour appears to shorten labor duration.

Keywords: Intra-Muscular Administration - Dexamethasone - Primigravida Full-Term Pregnancy

\section{INTRODUCTION}

Induction of labor is one of the most common interventions practiced in modern obstetrics. In the developed World, the ability to induce labor has contributed to the reduction in maternal and perinatal mortality and morbidity ${ }^{(1)}$.

The goal of labor induction is to stimulate uterine contractions before the spontaneous onset of labor, resulting in vaginal delivery. The benefits of labor induction must be weighed against the potential maternal and fetal risks associated with this procedure. When the benefits of expeditious delivery are greater than the risks of continuing the pregnancy, inducing labor can be justified as a therapeutic intervention ${ }^{(2)}$.

The success of induction and labor progression is dependent on the condition of the cervix before induction initiation ${ }^{(2)}$.

In primigravidae, the mean time taken from induction to delivery is between 15 and 20 hours, of which up to 12 hours is spent in the cervical ripening phase before labor itself starts (1).

About 10 percent of pregnancies may be prolonged. In general, the longer the truly post-term fetus stays in the uterus, the greater the risk of a severely compromised fetus and newborn infant. Therefore of major importance in handling compromised postdate pregnancies is the use of a suitable method of labor induction ${ }^{(3)}$.

A prolonged gestation is more likely to occur when the fetus has congenital adrenal hyperplasia caused by 21-hydroxylase deficiency, which may be due to an impaired cortisol production ${ }^{(4)}$.

Glucocorticoids are now known to play key roles in fetal maturation for example in maturation of the lung in anticipation of extrauterine life and in several species appear to be mediators in the initiation of labor. In humans, the placenta synthesizes $\mathrm{CRH}$, and the exponential rise of this hormone in maternal plasma correlates with the timing of birth ${ }^{(5)}$.

Glucocorticoids derived from the maturing fetal hypothalamus-pituitary-adrenal axis play a crucial role in triggering parturition (6).

Different studies have shown the paracrine and autocrine effects of corticosteroids on the human uterus, and receptors for these agents have been detected on the human amniotic membranes ${ }^{(7)}$.

The corticotrophin-releasing hormone $(\mathrm{CRH})$, which has been identified in various 
organ systems, including the female reproductive system, is the principal regulator of the hypothalamic-pituitary-adrenal axis. Circulating placental CRH is responsible for the physiologic hypercortisolism of the latter half of pregnancy and plays a role in the onset of labor ${ }^{(8)}$.

During pregnancy, large amounts of $\mathrm{CRH}$ are released from the placenta and fetal membranes. An increment in plasma CRH concentration occurs during spontaneous labor, with peak value at vaginal delivery. Placental $\mathrm{CRH}$ is also released into the fetal circulation, dehydroepiandrosterone and in vitro CRH directly stimulates sulfate (DHEA-S) production from the fetal zone of the fetal adrenal ${ }^{(5)}$.

This increase in fetal zone activity correlates with rising levels of maternal estrogen levels through the conversion of DHEA-S to estrogens within the placenta. The increase in the maternal estrogen to progesterone ratio may promote the expression of contraction-associated proteins in the myometrium, thus facilitating the initiation of parturition ${ }^{(9)}$.

Cortisol increases the production of prostaglandins in the fetal membranes by either up regulating prostaglandin synthesis (PGHS2) levels or down regulating 15-hydroxy prostaglandin dehydrogenase (PGDH) ${ }^{(4)}$.

It has been very well recognized that increased prostaglandin $\left(\mathrm{PGE}_{2}\right.$ and $\left.\mathrm{PGF}_{2}\right)$ biosynthesis as a result of inflammation-like responses in intrauterine tissues is one of the key events leading to parturition in both term and preterm human labor because these compounds evoke uterine contractions as well as cervical softening and effacement ${ }^{(\mathbf{8})}$.

Human fetal membranes are generally regarded as the major sources of prostaglandins at the end of pregnancy. However, it is not clear whether SP-A affects prostaglandin synthesis in human fetal membranes ${ }^{(\mathbf{8})}$.

Therefore, glucocorticoids also play an important role in human parturition. This cascade of events initiated by glucocorticoids may play an important role in the positive feedforward mechanisms.

\section{AIM OF THE WORK}

To establish whether a single dose of dexamethasone (8mg) intra-muscularly plays a role in shorting the duration interval between initiation of labor induction and beginning of the active phase of labor in primigravida fullterm pregnancy.

\section{PATIENTS AND METHODS}

This is a prospective clinical interventional randomized case-controlled trial was conducted at El Hussien University Hospital during the period from July 2017 to March 2018. The study was approved by the Ethics Board of Al-Azhar University.

The inclusion criteria in the study are:

- Singleton pregnancy.

- Post-term gestation i.e. 40 weeks or more.

- Sure, reliable dates.

- Favorable cervix with Bishop score of 7 or greater.

- Longitudinal lie.

- Cephalic presentation (Vertex).

The exclusion criteria in the study are:

- Abnormal presentation.

- Multiple pregnancies.

- Active phase of labour.

- Cephalo-pelvic disproportion.

- History of previous C-section or myomectomy operation.

- Known contraindication or hypersensitivity to Dexamethasone.

- Current fetal distress.

- Current maternal disorder e.g. diabetes mellitus, pregnancy induced hypertension.

- Over distended abdomen e.g. fetal macrosomia or polyhydramonus suggested by U/S or estimated fetal weight by expert hand.

- Significant vaginal bleeding.

Methods (plan):

The study included 120 participants whom were admitted for labor induction at El Hussien University Hospital.

The participants were randomly assigned by computer list into Group I (Dexamethasone group) $\mathrm{N}=60$ and Group II (Control group) $\mathrm{N}=60$.

The participants of Group I were received a prefilled syringe with two milliliters $(8 \mathrm{mg})$ of dexamethasone intra-muscular, and the participants of Group II were not receive dexamethasone or any other cervical ripening agent.

No cervical ripping agent was used for induction of labor in either group.

After approval of health committee in El Hussien University Hospital, a verbal 
consent was obtained from each candidate after explanation of the procedure in details.

\section{The steps were conduct as follows:}

I- Clinical history was obtained.

II- Monitoring for maternal wellbeing:
a) Pulse rate.
b) Blood pressure
c) Temperature.
d) Any other maternal complaint i.e. Nausea, vomiting, palpitation, headache, etc. was noticed.

III- Monitoring of fetal well-being:

a) Application of CTG half an hour to all participates before starting any intervention.

b) Color of amniotic fluid in those with rupture of membranes.

IV- Per vaginal examination to assess:

a) Cervical dilatation and effacement at the beginning.

b) State of fetal membranes.

c) Station of fetal head.

d) Position of fetal head.

e) Pelvic adequacy.

V- Each participant was receive a prefilled syringe with two milliliters of colorless solution intramuscular [either Dexamethasone $(8 \mathrm{mg})$ or placebo] randomly assigned by computer list.

VI- After six hours of the initial dose, the labor induction was start via Oxytocin using the following protocol:
a) Initial dose of oxytocin........................................ 1 to $2 \mathrm{mIU} / \mathrm{min}$.
b) Increase interval. ...30 minutes.
c) Dosage increment .....1 to $2 \mathrm{mIU}$.
d) Usual dose for good labour..................................... to to12 $\mathrm{mIU} / \mathrm{min}$. ................................................
$\mathrm{mIU} / \mathrm{min}$.
e) Maximum dose

VII- The interval between the initiation of induction and the beginning of the active phase of labor is recorded (a cervical dilatation of $4 \mathrm{~cm}$ plus 3 forceful contractions over a 10-minute span each last from 40-60 Sec).
VIII- Partographic representation for progression of active phase labor:

a) Frequency and duration of uterine contraction.

b) Cervical dilatation will record every two hours by per vaginal examination.

c) Station and position of fetal head was noted at the same time.

\section{IX- After delivery:}

a) The duration of the first stage of labor was recorded (Partographic representation was done for each participant).

b) The duration of the second stage of labor was recorded.

c) The duration of the placental separation was recorded.

d) The neonatal outcome was recorded by APGAR score.

e) Any postpartum maternal adverse effect was noted (e.g. vital sing abnormality, any maternal postpartum hemorrhage and CNS manifestation).

Primary outcomes:

The interval between the initiation of induction and the beginning of the active phase of labor was recorded (a cervical dilatation of 4 $\mathrm{cm}$ plus 3 forceful contractions over a 10minute span each last from 40-60 Sec).

Secondary outcomes:

(a) The duration of the first stage of labor wasrecorded (Partographic representation will do for each participant).

(b) The duration of the second stage of labor was recorded.

(c) The duration of the placental separation was recorded.

(d) The neonatal outcome was recorded by APGAR score.

(e) Any postpartum maternal adverse effect was noted (e.g. vital sing abnormality, any maternal postpartum hemorrhage and central nervous system manifestation).

\section{Statistical analysis}

All clinical and demographic data will be recorded on investigative report form. These data will be analyzed by IBM computer using SPSS (Statistical program for social science version 12) as follows:

Description of quantitative (numerical) variables was performed in the form of mean, standard deviation (SD) and range. 
Effect of Intra-Muscular Administration of Dexamethasone on the Duration of Induction...

Description of qualitative (categorical) variables was performed in the form number of cases and percentage.

Chi-square test was used to compare qualitative variables between groups.

Fisher exact test was used instead of chi-square when one expected cell or more less than five.

RESULTS

Descriptive Statistics

Table (1): Demographic characteristics of the patients (mean \pm SD)

\begin{tabular}{|c|c|c|c|c|}
\hline & $\begin{array}{c}\text { Dexamethasone } \\
\text { group }(\mathbf{n = 6 0})\end{array}$ & $\begin{array}{c}\text { Control group } \\
(\mathbf{n = 6 0})\end{array}$ & p-value & Sig. \\
\hline Age (years) & $26 \pm 4.36$ & $25.63 \pm 3.79$ & $0.624^{*}$ & N.S. \\
\hline BMI (Kg/m $\left.{ }^{2}\right)$ & $23.09 \pm 1.89$ & $22.78 \pm 1.71$ & $0.344^{*}$ & N.S. \\
\hline $\begin{array}{c}\text { Gestational age on } \\
\text { admission (weeks) }\end{array}$ & $40 \pm 1.46$ & $40 \pm 1.35$ & $0.796^{*}$ & N.S. \\
\hline
\end{tabular}

Values are mean \pm S.D. S.D.: Standard Deviation; N.S.: Non-significant, *Student t-test

There were non-significant statistical differences between the two studied groups as regard age, body mass index (BMI), gestational age.

Table (2): Statistical comparison between the two studied groups as regards pulse and blood pressure (vital signs)

\begin{tabular}{|c|c|c|c|c|}
\hline & Dexamethasone group (n=60) & Control group $(\mathbf{n = 6 0})$ & p-value & Sig. \\
\hline Pulse (bpm) & $79.07 \pm 6.09$ & $79.4 \pm 5.13$ & $0.746^{*}$ & N.S. \\
\hline Systolic BP & $118 \pm 14.59$ & $118 \pm 13.38$ & $1.000^{*}$ & N.S. \\
\hline Diastolic BP & $72.5 \pm 8.31$ & $73 \pm 8.69$ & $0.748^{*}$ & N.S. \\
\hline
\end{tabular}

Values are Mean \pm S.D. *Student t-test

S.D.: Standard Deviation; N.S.: Non-significant; bpm: Beat per minutes; BP: Blood Pressure

There were non-significant statistical differences between the two groups as regard pulse and blood pressure (vital signs).

Table (3): Statistical comparison between the two studied groups as regards Bishop score at time of intervention

\begin{tabular}{|c|c|c|c|c|}
\hline & $\begin{array}{l}\text { Dexamethasone } \\
\text { group }(n=60)\end{array}$ & Control group $(n=60)$ & p-value & Sig. \\
\hline Cervical dilatation $(\mathrm{cm})$ & $2.43 \pm 0.72$ & $2.5 \pm 0.62$ & $0.589 *$ & N.S. \\
\hline Effacement (\%) & $43.33 \pm 7.05$ & $44 \pm 10.61$ & $0.686^{*}$ & N.S. \\
\hline $\begin{array}{c}\text { Consistency } \\
\text { Firm } \\
\text { Intermediate } \\
\text { Soft } \\
\end{array}$ & $\begin{array}{c}2(3.3 \%) \\
22(36.7 \%) \\
36(60 \%) \\
\end{array}$ & $\begin{array}{c}4(6.7 \%) \\
26(43.3 \%) \\
30(50 \%) \\
\end{array}$ & $0.462 * *$ & N.S. \\
\hline $\begin{array}{c}\text { Position } \\
\text { Posterior } \\
\text { Central } \\
\text { Anterior } \\
\end{array}$ & $\begin{array}{c}4(6.7 \%) \\
32(53.3 \%) \\
24(40 \%) \\
\end{array}$ & $\begin{array}{c}4(6.7 \%) \\
30(50 \%) \\
26(43.3 \%) \\
\end{array}$ & $0.930 * *$ & N.S. \\
\hline $\begin{array}{c}\text { Station of fetal head } \\
-2 \\
-1 \\
0 \\
+1 \\
\end{array}$ & $\begin{array}{c}16(26.7 \%) \\
6(10 \%) \\
32(53.3 \%) \\
6(10 \%) \\
\end{array}$ & $\begin{array}{c}16(26.7 \%) \\
16(10 \%) \\
22(36.7 \%) \\
6(10 \%)\end{array}$ & $0.094 * *$ & N.S. \\
\hline Total Bishop score & $7.63 \pm 0.66$ & $7.63 \pm 0.71$ & $1.000 *$ & N.S. \\
\hline
\end{tabular}

Values are mean \pm S.D. \& number $(\%) \quad *$ Student t-test

S.D.: Standard Deviation; **Chi-square test; N.S.: Non-significant

There were non-significant statistical differences between the two groups as regard cervical dilatation, effacement, cervical position, consistency, head station and total Bishop score.

Table (4): Statistical comparison between the two studied groups as regards duration between induction of labor and active phase 


\begin{tabular}{|c|c|c|c|c|}
\hline & $\begin{array}{c}\text { Dexamethasone group } \\
(\mathbf{n = 6 0})\end{array}$ & $\begin{array}{c}\text { Control group } \\
(\mathbf{n = 6 0})\end{array}$ & p-value & Sig. \\
\hline $\begin{array}{c}\text { Duration between induction } \\
\text { of labor and active phase } \\
\text { (hr.) }\end{array}$ & $2.54 \pm 0.94$ & $3.59 \pm 0.86$ & $0.001 *$ & H.S. \\
\hline
\end{tabular}

Values are mean \pm SD $\quad$ *Student t-test $\quad$ S.D.: Standard Deviation; H.S.: Highly Significant

Dexamethasone group shows shorter duration between labor induction and active phase of labor than control group (2.54 $\pm 0.94 \mathrm{hr}$. vs. $3.59 \pm 0.86 \mathrm{hr}$.).

There was a high significant statistical difference between the two studied groups as regards duration between labor induction and active phase of labor ( $\mathrm{p}$ less than 0.001 ).

Table (5): Statistical comparison between the two studied groups as regards duration of active phase of labor

\begin{tabular}{|c|c|c|c|c|}
\hline & $\begin{array}{c}\text { Dexamethasone } \\
\text { group (n=60) }\end{array}$ & $\begin{array}{c}\text { Control } \\
\text { group (n=60) }\end{array}$ & value & p- \\
\hline $\begin{array}{c}\text { Duration of } \\
\text { active phase of labor (hrs.) }\end{array}$ & $4.82 \pm 0.56$ & $5.12 \pm 0.58$ & $0.006^{*}$ & \\
\hline
\end{tabular}

Values are mean \pm S.D. * *Student t-test S.D.: Standard Deviation; S: Significant

Dexamethasone group shows shorter duration of active phase of labor than control group (4.82 \pm 0.56 hr. vs. $5.12 \pm 0.58 \mathrm{hr}$.).

There was a significant statistical difference between the two studied groups as regards duration of active phase of labor ( $\mathrm{p}$ less than 0.05 ).

Table (6): Statistical comparison between the two studied groups as regards duration of 1st stage of labor

\begin{tabular}{|c|c|c|c|c|}
\hline & Dexamethasone group $(\mathbf{n}=\mathbf{6 0})$ & Control group $(\mathbf{n}=\mathbf{6 0})$ & p-value & Sig. \\
\hline Duration of 1 ${ }^{\text {st }}$ stage of labor (hr.) & $7.35 \pm 1.15$ & $8.69 \pm 1.09$ & $0.001^{*}$ & S \\
\hline
\end{tabular}

Dexamethasone group shows shorter duration of first stage of labor than control group $(7.35 \pm 1.15 \mathrm{hr}$. vs. $8.69 \pm 1.09 \mathrm{hr}$.).

There was a significant statistical difference between the two studied groups as regards duration of first stage of labor (p less than 0.001).

Table (7): Statistical comparison between the two studied groups as regards rate of cervical dilatation

\begin{tabular}{|c|c|c|c|c|}
\hline & Dexamethasone group $(\mathbf{n}=\mathbf{6 0})$ & Control group $(\mathbf{n}=\mathbf{6 0})$ & p-value & Sig. \\
\hline Rate of cervical dilatation (cm/hour) & $1.37 \pm 0.18$ & $1.28 \pm 0.17$ & $0.01 *$ & $S$. \\
\hline
\end{tabular}

Values are mean \pm S.D. $\quad *$ Student t-test $\quad$ S.D.: Standard Deviation; S.: Significant

Dexamethasone group shows faster rate of cervical dilatation than control group $(1.37 \pm 0.18$ $\mathrm{cm} / \mathrm{hr}$. vs. $1.28 \pm 0.17 \mathrm{~cm} / \mathrm{hr}$.).

There was a significant statistical difference between the two studied groups as regards rate of cervical dilatation ( $\mathrm{p}$ less than 0.05 ).

Table (8): Statistical comparison between the two studied groups as regards duration of $2^{\text {nd }}$ stage of labor

\begin{tabular}{|c|c|c|c|c|}
\hline & Dexamethasone group $(\mathbf{n}=\mathbf{6 0})$ & Control group $(\mathbf{n}=\mathbf{6 0})$ & p-value & Sig. \\
\hline Duration of 2nd stage of labor (minutes) & $25.09 \pm 12.99$ & $30.73 \pm 12.96$ & $0.032 *$ & $\mathrm{~S}$ \\
\hline
\end{tabular}
Values are mean \pm S.D. *Student t-test
$\begin{aligned} & \text { S.D.: Standard Deviation; S.: Significant } \\
& \text { Dexamethasone group shows shorter duration of second stage of labor than control group }\end{aligned}$

$(25.09 \pm 12.99$ minutes vs. $30.73 \pm 12.96$ minutes $)$.

There was a significant statistical difference between the two studied groups as regards duration of second stage of labor (p less than 0.05).

Table (9): Statistical comparison between the two studied groups as regards dose of oxytocin required

\begin{tabular}{|c|c|c|c|c|}
\hline & Dexamethasone group & Control group & p-value & Sig. \\
\hline Oxytocin requirement (hours) & $5.35 \pm 1.49$ & $5.97 \pm 1.34$ & $0.019^{*}$ & $\mathrm{~S}$ \\
\hline
\end{tabular}

Values are mean \pm S.D. $\quad *$ Student t-test $\quad$ S.D.: Standard Deviation; S.: Significant

Oxytocin requirement in dexamethasone group was less than in control group $(5.35 \pm 1.49$ hours vs. 5.97 \pm 1.34 hours).

There was a significant statistical difference between the two studied groups as regards dose of oxytocin required ( $\mathrm{p}$ less than 0.05 ). 
Effect of Intra-Muscular Administration of Dexamethasone on the Duration of Induction...

Table (10): Statistical comparison between the two studied groups as regards duration of $3^{\text {rd }}$ stage of labor

\begin{tabular}{|l|c|c|c|c|}
\hline & Dexamethasone group $(\mathbf{n}=\mathbf{6 0})$ & Control group $(\mathbf{n}=\mathbf{6 0})$ & p-value & Sig. \\
\hline Duration of $3^{\text {rd }}$ stage of labor (minutes) & $8.57 \pm 3.63$ & $9.52 \pm 2.99$ & $0.155^{*}$ & N.S. \\
\hline
\end{tabular}

Values are mean \pm S.D. *Student t-test $\quad$ S.D.: Standard Deviation; S.: Significant

There was no significant statistical difference detected between the two studied groups as regards duration of $3^{\text {rd }}$ stage of labor.

Table (11): Statistical comparison between the two studied groups as regards mode of delivery and its indication

\begin{tabular}{|c|c|c|c|c|}
\hline Mode of delivery and indication & $\begin{array}{c}\text { Dexamethasone group } \\
(\mathbf{n = 6 0 )}\end{array}$ & $\begin{array}{c}\text { Control group } \\
(\mathbf{n = 6 0 )}\end{array}$ & $\begin{array}{c}\mathbf{p}- \\
\text { value }\end{array}$ & Sig. \\
\hline SVD & $\begin{array}{c}50 \\
(83.3 \%)\end{array}$ & $0.43 * *$ & N.S. \\
\hline C.S. & $10(16.7 \%)$ & $14(23.3$ & & \\
Failed induction & $2(20 \%)$ & $5(35.7 \%)$ & & \\
Failure to progress & $2(20 \%)$ & $3(21.4 \%)$ & & \\
Fetal distress & $4(40 \%)$ & $5(35.7 \%)$ & & \\
Deep transverse arrest (direct occipito- & $1(10 \%)$ & $0(0.0 \%)$ & & \\
transverse) & & & \\
\hline
\end{tabular}

Values are numbers (percentage), ${ }^{* *}$ Chi-square test

N.S.: Non-significant; SVD: Spontaneous vaginal delivery; C.S.: Caesarean section of delivery.

There was a non-significant statistical difference between the studied groups as regards mode

Table (12): Statistical comparison between the two studied groups as regards neonatal outcome

\begin{tabular}{|c|c|c|c|c|}
\hline & Dexamethasone group (n=60) & Control group (n=60) & p-value & Sig. \\
\hline Birth weight (gm.) & $3150 \pm 255.12$ & $3190 \pm 271.34$ & $0.407^{*}$ & N.S. \\
\hline Apgar score at 1 minute & $7.23 \pm 0.69$ & $7.1 \pm 0.66$ & $0.283^{*}$ & N.S. \\
\hline Apgar score at 5 minutes & $8.7 \pm 0.72$ & $8.65 \pm 0.71$ & $0.702^{*}$ & N.S. \\
\hline $\begin{array}{c}\text { Fetal heart rate disturbance } \\
\text { Yes }\end{array}$ & $7(11.67 \%)$ & $6(10 \%)$ & & \\
No & $53(88.33 \%)$ & $54(90 \%)$ & $0.769^{* *}$ & N.S. \\
\hline $\begin{array}{c}\text { Meconium-stained liquor } \\
\text { Yes }\end{array}$ & $3(5 \%)$ & $4(6.67 \%)$ & & \\
No & $57(95 \%)$ & $56(93.33 \%)$ & $0.697^{* *}$ & N.S. \\
\hline $\begin{array}{c}\text { Admission to NICU } \\
\text { Yes }\end{array}$ & $\begin{array}{c}6(10 \%) \\
54(90 \%)\end{array}$ & & N.S. \\
No & $56(93.3 \%)$ & & \\
\hline
\end{tabular}

Values are mean \pm SD \& number (\%), *Student t-test, ${ }^{* *}$ Chi-square test

S.D.: Standard Deviation; N.S.: Non-significant; NICE: Neonatal intensive care unit

There were non-significant statistical difference between the two studied groups as regards birth weight, Apgar score at 1 minute, Apgar score at 5 minutes, fetal heart rate disturbance, meconium stained liquor \& admission to NICU.

\section{DISCUSSION}

It is well known that glucocorticoids accelerate lung maturation by enhancing surfactant synthesis in the pulmonary alveolar cells. Evidence has been obtained from early studies that the phospholipid content of surfactant provides a source of arachidonic acid that can be used by the amnion for prostaglandin synthesis. Recently there is direct evidence pointing to surfactant protein A (SPA) as the key link between the maturing fetus and the initiation of parturition in the mouse ${ }^{(9)}$.
Glucocorticoids derived from the maturing fetal hypothalamus-pituitary-adrenal axis play a crucial role in, triggering parturition (6).

In humans, the placenta synthesizes corticotrophin-releasing hormone $(\mathrm{CRH})$, and the exponential rise of this hormone in maternal plasma correlates with the timing of birth ${ }^{(\mathbf{1 0})}$.

The $\mathrm{CRH}$, which has been identified in various organ systems, including the female reproductive system, is the principal regulator of the hypothalamic-pituitary-adrenal axis. Circulating placental $\mathrm{CRH}$ is responsible for the physiologic hypercortisolism of the latter half of pregnancy and plays a role in the onset of labor ${ }^{(8)}$.

Cortisol increases the production of prostaglandins in the fetal membranes by either up regulating prostaglandin synthesis levels or 
down regulating 15-hydroxy prostaglandin dehydrogenase (PGDH) ${ }^{(\mathbf{1 1})}$.

Therefore, glucocorticoids also play an important role in human parturition. In the fetal membranes, the actions of glucocorticoids are amplified by the actions of $11 \beta$-HSD steroid

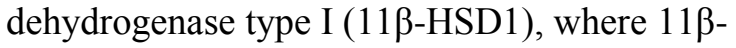
HSD1 converts biologically inert cortisone to active cortisol thereby increasing the local levels of biologically active glucocorticoids. This cascade of events initiated by glucocorticoids may play an important role in the positive feed-forward mechanisms ${ }^{(11)}$.

This case controlled trial study was been conducted in the labor ward of El Hussien University Hospital to evaluate the effect of intramuscular dexamethasone administration on the duration of labor.

This study comprised 120 pregnant women with full term pregnancy, who admitted to the labor ward for induction of labor because of full-term pregnancy (gestational age $\geq 40$ weeks).

Pregnant women were randomized (assigned) to receive dexamethasone sodium phosphate $8 \mathrm{mg}(2 \mathrm{ml})$ or receive nothing or any other cervical ripening agent.

\section{As regarding our results:}

The study showed there were no significant statistical difference between the two studied groups regarding the mean maternal age (years), the gestational age (weeks) on admission, pulse (beat per minute) and blood pressure; No such difference was found regarding body mass index (BMI) and percentage of cesarean section between the two studied groups.

In addition, there were non-significant statistical differences between the two groups as regard primary Bishop score (cervical dilatation, effacement, cervical position, consistency, head station and total Bishop score).

The present study showed that a dexamethasone injection intramuscularly has suggested no significant difference between the 2 groups in the duration of the third stage of labor \& the neonatal outcome (Birth weight, APGAR score at 1 minute and 5 minutes, number of cases with fetal heart rate disturbance, meconium stained liquor \& neonatal admission to neonatal intensive care unit).
The first stage of labor was shorter in dexamethasone group than control group ( $7.35 \pm 1.15$ hrs. vs. $8.69 \pm 1.09$ hrs.) $(\mathrm{p}=0.001)$.

The second stage of labor was shorter in the dexamethasone group than in control group $(25.09 \pm 12.99$ minutes vs. $30.73 \pm 12.96$ minutes) $(\mathrm{p}=0.032)$. The interval between the initiation of labor induction and the beginning of the active phase of labor was $2.54 \pm 0.94$ hours in the dexamethasone group and $3.59 \pm 0.86$ hours in the control group, and the difference was significant ( $\mathrm{p}$-value less than $0.001)$.

The duration of active phase of labor was $4.82 \pm 0.56$ hours in dexamethasone group and 5.12 \pm 0.58 hours in control group, and the difference was significant ( $\mathrm{p}$ value less than $0.05)$.

The rate of cervical dilatation is faster in dexamethasone group than control group $(1.37 \pm 0.18 \mathrm{~cm} / \mathrm{hr}$. vs. $1.28 \pm 0.17 \mathrm{~cm} / \mathrm{hr}$.), the difference was significant ( $\mathrm{p}=0.01$ ).

The mean oxytocin dose consumption on entering active phase was $5.35 \pm 1.49$ units for dexamethasone group and $5.97 \pm 1.34$ unites for control group and the difference was significant $(\mathrm{p}=0.019)$.

Our findings are in agreement with those observed by Kashanian et al. ${ }^{(12)}$ who evaluated the effect of dexamethasone administration on labor duration. A controlled trial including 122 nulliparous women with a full-term pregnancy and a Bishop score of 7 or greater, were randomly assigned to receive a single $8 \mathrm{mg}$ dose of dexamethasone for the case group or placebo for the control group 6 hours before initiation of labor induction.

They found that the interval between initiation of labor induction and beginning of the active phase of labor was shorter in the dexamethasone than in the control group. The duration of the second stage of labor was also shorter in the dexamethasone group. They concluded that the administration of dexamethasone was found to shorten labor duration by decreasing the interval between the induction and the beginning of the active phase, with no observed maternal or neonatal complications ${ }^{(\mathbf{1 2})}$.

Kashanian et al. ${ }^{(12)}$ reported on the extra-amniotic infusion of a saline solution mixed with dexamethasone through a Foley catheter whose balloon was filled with $15 \mathrm{ml}$ of water, and concluded that the procedure could 
shorten the duration of labor without significant maternal or fetal risk.

O'Sullivan et al. ${ }^{(4)}$ concluded that fetuses with congenital adrenal hyperplasia due to 21-hydroxylase deficiency were more likely to have a prolonged gestation, and this may be due to impaired cortisol production.

Hajivandi et al. ${ }^{(13)}$ performed clinical trial on 100 eligible nulliparous women in their 40 to 42 weeks of gestation in 2009 who were admitted to Amir Hospital in Ahvaz. For the case group, $8 \mathrm{mg}$ dexamethasone was administered 12 hours before induction and the controls were given $2 \mathrm{ml}$ of normal saline at the same intervals.

There was no significant difference between the two groups in terms of age, demographic characteristics, initial Bishop score, first and fifth minute Apgar score, and meconium difference. There was a significant difference between the two groups $(\mathrm{p}=0.001)$ concerning the mean-time interval between the induction and the onset of active phase in the case group (3.1 \pm 0.68 hours) and in the control group it was (4.2 \pm 1.3 hours). They concluded that intra-muscular dexamethasone reduces the time duration from the induction to the onset of labor phase ${ }^{(13)}$.

In another study, conducted by Ziaee et al. ${ }^{(14)}$, that aimed to determine the effect of intra-muscular injection of dexamethasone on induction of labor. Women in 41 weeks gestational age and Bishop score greater than or equal to 7 received intramuscular injections of $10 \mathrm{mg}$ dexamethasone in two doses with 12 hours interval, and the next day, induction was carried out using oxytocin. These patients were compared with patients in similar conditions, but receiving oxytocin.

In this study, more of the patients from dexamethasone group entered active phase than that in control group, and interval between induction and onset of active phase was shorter in this group than in control group. They reported that intra-muscular injection of dexamethasone before labor induction reduced the time between the induction and the active phase of labor ${ }^{(14)}$.

Also, $90.25 \%$ of dexamethasone group entered active phase, and $88.37 \%$ of control group, but the difference was insignificant. Mean onset of oxytocin to delivery was $7.25 \pm 2.86$ hours in the case group, and $9.76 \pm 3.91$ hours in the control group, with a significant difference between the two groups $(\mathrm{p}=0.002)$. Results of this study showed that injection of extra-amniotic normal saline was a suitable and inexpensive method for cervical ripening and response to induction. The addition of dexamethasone could help to shorten delivery process and that inducing labor by means of an extra-amniotic infusion of corticosteroids through an intra-cervical Foley balloon catheter reduced the time between induction of labor and delivery. This may indicate a possible role for corticosteroids in the parturition process.

This goes with Zafarghandi et al. ${ }^{(15)}$ who challenged the possible role of corticosteroids in induction of labor by extraamniotic injection through an inflated intracervical Foley balloon catheter. This randomized trial was conducted on 44 women with a single pregnancy, intact membranes, and an unfavorable cervix.

They were randomly assigned to receive either $20 \mathrm{mg}$ of dexamethasone in saline solution (study group, $n=22$ ) or saline solution only (control group, $n=22$ ) administered extraamniotically through an intra-cervical inflated Foley balloon catheter. Eighteen (81.8\%) patients in the study group and twenty (90.9\%) in the control group entered the active phase of labor and were delivered vaginally. The mean time intervals between induction of labor to the active phase and between induction of labor to delivery were significantly shorter in the study group compared with those of the control group (3.3 \pm 2.1 hours vs. $9 \pm 4.7$ hours, $\mathrm{p}<0.01,5.7 \pm 3.4$ hours vs. $6.9 \pm 4.7$ hours, $\mathrm{p}<0.01$, respectively). There was no maternal or fetal complication in study or control group.

They concluded that the intra-cervical Foley balloon catheter with extra-amniotic corticosteroids was more efficient in reducing the induction-to-delivery interval for termination of mid-trimester pregnancies than the same Foley catheter with saline solution only. Cervical ripening with extra-amniotic corticosteroids possesses the advantages of simplicity, low cost, lack of systemic or serious side effects ${ }^{(15)}$.

This goes with Mansouri et al. ${ }^{\left({ }^{(16)}\right.}$ who tried to show the effect of extra-amniotic administration of corticosteroids to shorten the times to either active labor and/or delivery. This is a double blind randomized study. 65 patients who were candidates for the termination of pregnancy between the ages of 16-45, with intact membranes and unripe cervix were 
randomly divided into two groups, a study group $(\mathrm{n}=34)$ and a control group $(\mathrm{n}=31)$.

In the study group, $20 \mathrm{mg}$ of dexamethasone was infused through a Foley catheter into the extra-amniotic space and the infusion was continued with normal saline in both groups. The result of the study showed that the interval of induction to active phase of labor was shorter in the study group compared to control group. The interval of induction to delivery was shorter in the study group compared to the control group. They concluded that corticosteroids might have a role in shortening the interval of induction to active phase of labor and the interval of induction to delivery ${ }^{(\mathbf{1 6})}$.

Sciscione ${ }^{(17)}$ showed that using a Foley catheter is useful for pre-induction cervical ripening and advised to be used in outpatient versus inpatient setting.

In contrast to our results, Kavanagh et al. (7) in a review study on the effect of corticosteroids in cervical ripening and induction of labor concluded that, efficacy of corticosteroids in induction of labor was still unknown and required further studies. In 2006, they extended their studies, but arrived at the same conclusion.

\section{CONCLUSION}

Single intra-muscular injection of two $\mathrm{ml}$. (8mg.) of dexamethasone before induction of labour appears to shorten labor duration.

\section{REFERENCES}

1. Subramanian $V$ and Penna $D$ (2009): Best Practice in Labor and Delivery. ${ }^{\text {st }}$ ed. Published by Cambridge University Press: Induction of labor; Edited by Warren R. and Arulkumaran S., Cambridge University Press; Ch 18.

2. Barclay L (2009): The American College of Obstetricians and Gynecologists (ACOG) issued revised guidelines on when and how to induce labor in pregnant Women. The updated recommendations are published as a Practice Bulletin\#107 "Induction of Labor", in the August issue of Obstetrics \& Gynecology, 6(4): 65-75.

3. Petraglia F, Imperatore $A$ and Challis JR (2010): Neuroendocrine mechanisms in pregnancy and parturition. Endocr Rev., 31(6): 783-816.

4. O'Sullivan J, Iyer S, Taylor $\mathbf{N}$ et al. (2007): Congenital adrenal hyperplasia due to 21-hydroxylase deficiency is associated with a prolonged gestational age. Arch Dis Child., 92(8): 690-2.

5. Falah $N$ and Haas DM (2014): Antenatal corticosteroid therapy: current strategies and identifying mediators and markers for response. Semin Perinatol., 38(8): 528-33.

6. Challis JRG, Matthews SG, Gibb W et al. (2000): Endocrine and paracrine regulation of birth at term and preterm. Endocr Rev., 21: 514-550.

7. Kavanagh J, Kelly AJ and Thomas J (2006): Corticosteroids for cervical ripening and induction of labor. Cochrane Database Syst Rev., (2): CD003100.

8. Kalantaridou $\mathrm{S}$, Makrigiannakis $\mathrm{A}$, Zoumakis E et al. (2007): Peripheral corticotrophin-releasing hormone is produced in the immune and reproductive systems: actions, potential roles and clinical implications. Front Biosci., 12: 572-80.

9. Mastorakos G and Ilias I (2003): Maternal and fetal hypothalamicpituitary-adrenal axes during pregnancy and postpartum. Ann N Y Acad Sci., 997: 136-49.

10. Smith R (2007): Parturition. N Engl J Med., 356(3): 271-83.

11. Li Y, He P, Sun Q et al. (2013): Reduced expression of 15-hydroxy prostaglandin dehydrogenase in chorion during labor is associated with decreased PRB and increased PRA and GR expression; Am J Pathol., 182(5): 1585-94.

12. Kashanian $M$, Fekrat $M$, Naghghash $S$ et al. (2008): Evaluation of the effect of extra-amniotic normal saline infusion alone or in combination with dexamethasone for the induction of labor. Journal of Obstetrics and Gynaecology Research, 34(1): 47-50.

13. Hajivandi L, Montazeri S, Iravani M et al. (2013): Effect of intramuscular dexamethasone on onset of labor in postdates pregnancy. Journal of Babol University of Medical Sciences, 15(3): 24.

14. Ziaei S, Rosebehani N, Kazeminejad A et al. (2003): The effects of intramuscular administration of corticosteroids on the induction of parturition. Journal of Perinatal Medicine, 31(2): 134-9. 
Effect of Intra-Muscular Administration of Dexamethasone on the Duration of Induction...

15. Zafarghandi N, Hadavand S, Davati A et al. (2012): The effects of sleep quality and duration in late pregnancy on labor and fetal outcome. The Journal of Maternal-Fetal \& Neonatal Medicine, 25(5): 535-7.

16. Mansouri M, Pourjavad A and Panahi G (2003): Induction of labor with use of a
Foley catheter and extraamniotic corticosteroids. Medical Journal of the Islamic Republic of Iran , 17(2): 97-100.

17. Sciscione AC (2014): Methods of cervical ripening and labor induction: mechanical. Clin Obstet Gynecol., 57(2): 369-76. 